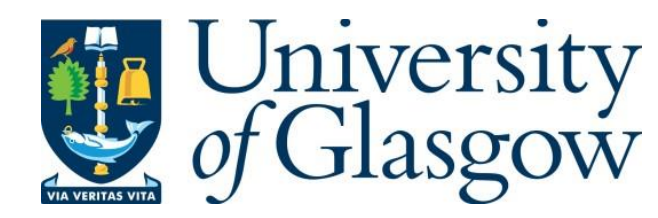

Brennan, M., Collinson-Scott, J., Connelly, A. and Lawrence, G. (2019) Do music festival communities address environmental sustainability and how? A Scottish case study. Popular Music, 38(2), pp. 252-275. (doi:10.1017/S0261143019000035)

There may be differences between this version and the published version. You are advised to consult the publisher's version if you wish to cite from it.

http://eprints.gla.ac.uk/166676/

Deposited on: 28 August 2018

Enlighten - Research publications by members of the University of Glasgow http://eprints.gla.ac.uk 
Article submission for Popular Music

Title: Do music festival communities address environmental sustainability and how? A Scottish case study.

Authors: Matt Brennan, Jo Collinson Scott, Angela Connelly, and Gemma Lawrence

Corresponding author:

Matt Brennan

Reid School of Music

Alison House

12 Nicolson Square

University of Edinburgh

Edinburgh EH8 9DF

Mobile telephone number: +447745449102

E-mail: m.t.brennan@ed.ac.uk 


\section{Do music festival communities address environmental sustainability and how? A Scottish case study.}

\section{Abstract}

This article discusses the findings of an Arts and Humanities Research Council project researching how music festival communities in Scotland can address issues of environmental sustainability and climate change. It investigates how music festival communities are constructed with a focus on what role, if any, they might play in responding to the global challenge of environmental sustainability. Using music festivals in Scotland as a case study, we employed a variety of research methods to interrogate different constituents in music festival communities about their views and behaviours regarding climate change and environmental sustainability. These included festival audiences via onsite questionnaires; festival organisers and promoters via interviews and focus groups; and musicians via creative practice-led research. We conclude that rather than necessarily being a site for progressive or utopian socio-cultural experimentation (as they are occasionally portrayed in festival literature), music festival communities engage in complex and often contradictory behaviours when it comes to responding to - and making sense of - their own complicity in social challenges such as climate change. 


\section{Introduction}

I'm going on down to Yasgur's farm, I'm going to join in a rock ' $n$ ' roll band I'm going to camp out on the land, I'm going to try and get my soul free. JONI MITCHELL, "WOODSTOCK" (1970)

20 kilotonnes of C02e annually (onsite emissions); 100 kilotonnes C02e annually, including audience travel; 23,500 tonnes waste; and 5 million litres of diesel consumption. ESTIMATED ANNUAL ENVIRONMENTAL IMPACT OF UK SUMMER MUSIC FESTIVALS, (JOHNSON 2015, p.5)

In October 2015, the UK Department of Energy and Climate Change issued a statement through the Arts and Humanities Research Council declaring that 'extensive robust scientific research discussing the causes and risks of climate change has not translated effectively into widespread action, committed public support or ownership over the issue ... [research is needed into] who the agents of influence are in public discussion, and what role the arts and the creative sector play' (AHRC 2015). In this article, we build on previous work investigating the relationship between music and the environment - and in particular recent work which considers the environmental impact of the music industries (e.g. Mair and Laing 2012; Cummings 2014; Johnson 2015) - as we report on a recent research project funded by the Arts and Humanities Research Council to examine what role, if any, music festival communities might play in addressing the contemporary challenge of environmental sustainability.

Since its early days in the 1960s, pop music festival culture has been concerned with the practice or at least rhetoric of care, nurture, and environmentalism. Andrew Kerr, for example, the organizer of the legendary 1971 Glastonbury Fair, published a pamphlet in which he explained to local residents the kind of event he hoped to promoted in their region that summer: 
It will be a fair in the medieval tradition, embodying the legends of the area, with music, dance, poetry, theatre lights and the opportunity for spontaneous entertainments. There will be no monetary profit - it will be free. Man is fast ruining his environment. He is suffering from the effects of pollution; from the neurosis brought about by a basically urban industrial society: from the lack of spirituality in his life. The aims are, therefore: the conservation of our natural resources; a respect for nature and life; and a spiritual awakening (quoted in Partridge 2013, p.128).

This article is therefore not simply an exploration of how values of environmentalism are negotiated in contemporary music festival culture. Instead, it explores the contradictions and challenges of the deployment of environmentalist values in rhetoric and practice through activism or avoidance, and corporate social responsibility or "greenwash" marketing - in contemporary music festival culture. Festivals derive cultural cachet from their historic association with environmental utopianism and the attraction of "getting back to the garden" (to paraphrase Joni Mitchell), but more often festival sites vividly dramatize the difficulty of living sustainably - a challenge that is all the more visible when rural landscapes are temporarily transformed into festival communities. In this way, festivals might be viewed not as getting back to the garden but as an invasion and transformation of the environment, with festival culture facing an uphill battle as it tries to square its own environmental legacy while reinventing itself for later generations and the demands of the contemporary live music industry.

What is the impact of a music festival? Webster and McKay have recently conducted a thorough literature review and grouped existing writing about the impact of British music festivals under eight headings: (1) economy and charity; (2) politics and power; (3) temporality and transformation; (4) creativity: music and musicians: (5) place-making and tourism; (6) mediation and discourse; (7) health and well-being; and (8) environment: global and local (2016, p.2). The majority of industry-funded research on festivals has unsurprisingly focused on their economic impact. According to a recent study by industry lobbying group UK Music, the total direct and indirect spend generated by music tourism on 
concerts and festivals reportedly amounted to £3.1 billion in 2014 in the UK alone (UK Music 2015, p.7). ${ }^{1}$ The economic impact of music festivals is also notable because the festival sector has enjoyed a substantial period of growth over the past two decades - a trend standing in contrast to the fortunes of the recording industry over the same period. Once taken for granted to be the most important component of the music industries (indeed, as Cloonan and Williamson [2007] have documented, the 'music industry' was virtually synonymous with the 'recording industry' for many years in both academic and industry accounts), the recording industry suffered from a period of economic instability and declining revenue between 2000 and 2010, while music festival revenues (not least through ticket prices in the USA and UK rising well above inflation) grew steadily in number during the same decade (Cloonan and Williamson 2007; Brennan and Webster 2010).

However, music festivals are not merely a key economic component of the wider music industries: they also carry a cultural legacy as sites where constituents of musical cultures gather to form temporary communities. As Webster and McKay have noted, British music festivals have historically often been 'sites for social and political debate, and sometimes action ... Festivals are or have been remarkable sites for experimenting with alternative lifestyles and practices' (2016, p.9). In Britain, this representation of pop festivals extends back to the 1950s and 1960s. Events such as the Beaulieu Jazz Festival and the National Jazz and Blues Festival created a template for weekend-long musical events where fans would camp overnight at a site to watch a programme of live music acts (Clarke 1982; McKay 2005). Music festivals quickly became an important part of popular music culture, not least because they acted as a beacon for fans to come together in the same physical space through shared musical tastes. By the late 1960s, pop festivals such as the Isle of Wight in the UK and Woodstock in the USA had become ideologically aligned (though not necessarily aligned in practice) with countercultural movements, escaping routines of mundane life, experimenting with alternative ways of living, and getting back to nature. Or as Webster and

\footnotetext{
${ }^{1}$ We use the word "reportedly" because valuations of the music industries are known to be difficult to calculate accurately. Nevertheless, this figure represents the best publicly available estimate at the time of writing.
} 
McKay have put it (summarizing a range of research on festival audiences), music festivals are discussed as "places for being with like-minded people and for engendering feelings of belonging, 'communitas', and community" (2016, p.10). The performance of songs themselves can also engage mass audiences directly around important issues by appealing to their emotions, and by engendering, as Anderson has put it, both "the ability to "feel" something better and the ability to "forget"' (Anderson 2002, p. 212). It has also been suggested that music creates a 'free space' for dialogue in public settings where debate and direct communication might otherwise be off putting (e.g. Pratt, 1994; Lipsitz, 1994). Yet, although popular music scholars have often considered the relationship between music and social movements including environmentalism (e.g. Pedelty 2012 and 2016), fewer experts from the field of environmental sustainability have examined what role songs and songwriters might play in addressing the challenge of climate change. This is one reason why, in addition to employing more traditional social research methods such as surveys, interviews, and focus groups, our research methodology also included a creative practice-led component in collaboration with festival artists

Pop festivals are also often commercial enterprises with organisers seeking to make a profit from ticket sales. In the economically competitive (and arguably saturated) UK festival landscape of the twenty-first century, festival promoters now work hard to construct identities for their events that distinguish them from rival festivals. Promoters frequently draw from the historical cultural cachet of music festivals to brand their events as experiences where audiences can seek temporary relief from the norms, routines, and constraints of modern society (Anderton 2015; Robinson 2015). Festivals have therefore often been constructed - both by marketing professionals and academics - as communities with their own distinct 'social rhythms' (Tjora 2016), taking on a variety of forms and identities ranging from hedonistic and carnivalesque escapes (e.g. BangFace Weekender, Beermageddon) to transient socially conscious utopian cities (e.g. Eden Festival, Glastonbury, the latter of which donates most of its profits to charities). 
Music festivals also have an environmental impact of course, from the temporary staging and infrastructure set up on green field sites to the carbon emissions caused by audience and artist travel. A 2007 study by Julie's Bicycle, the British cultural sector's leading environmental consultancy, estimated that the live music sector together with audience travel accounted for three-quarters ( 75\%) of the music industries' carbon emissions, with the greatest impact of all caused by large music festivals (Bottrill, Lye, Boykoff, and Liverman, 2007, p. 2). Meanwhile in a more recent study by Powerful Thinking (a UK-based organisation describing itself as a 'think-do tank which brings together festivals, suppliers and environmental organisations'), the UK festival industry's total known onsite carbon emissions amount to 19,778 tonnes per year (Johnson, 2015). However, since onsite emissions only account for $20 \%$ of a music festival's carbon footprint, if audience travel is taken into consideration then the figure increases substantially to approximately 97,930 tonnes annually (and even this figure does not include impacts from equipment transport and crew and artist travel). The evidence surrounding the environmental impact of music festivals therefore clashes strongly with representations - either historical or contemporary - of music festival communities moving closer towards ideals of environmental sustainability than our everyday routines. It is this contradiction that our project aimed to explore in greater detail.

Any aspirations towards environmental sustainability in the music festival sector are also completely at odds with the agenda of the growing music tourism industry. Over 9.5 million tourists traveled in the UK to listen to live music in 2014 , with 546,000 traveling from overseas (UK Music 2015, p.7). As Andy Heath, chairman of UK Music, has claimed:

The proportion of live audiences that are music tourists increased from $42 \%$ in 2011 to $45 \%$ in 2015. More international music tourists are coming to the UK and more Brits are travelling further afield to gigs. The average spend by international music tourists has increased by $13 \%$ in this period, while total UK exports have grown by less than $2 \%$. If we want an export-led recovery, we need music tourists to keep coming to the UK (ibid., p.10). 
When it came to music festivals, the report noted that 'overseas travellers shelled out nearly a grand when they camped out at a festival as part of their stay.' Such spending appears to be an increasingly integral part of the music industries' platform when lobbying for business support from the UK government. Indeed, Live Nation UK's Chief Operating Officer, Paul Latham, argued that audience travel and the resulting contributions to the UK economy from music tourism were essential for the well-being of the British recording industry as well - or as he put it in a turn of phrase that borrowed from the lexicon of environmental science, 'the music industry's ecosystem is now dependent on every part being successful' (ibid. p.9).

At this point it may be worth interrogating what exactly is meant by the term 'sustainability' in the context of the music industries. 'Sustainability' is a contested concept, and its malleability means that a range of different practices have emerged from under its umbrella (Redclift, 2005). Sustainability has traditionally been conceptualized in terms of three pillars which need to be balanced - specifically financial, environmental and social sustainability. More recently, there has been a movement towards the inclusion of 'culture' as a fourth pillar (Hawkes 2002). As Hawkes argues, 'cultural vitality is as essential to a healthy and sustainable society as social equity, environmental responsibility and economic viability' (ibid., p.10). The challenge of discussing the sustainability of the music industries is no different from other business sectors in this regard: environmental sustainability is viewed as a priority by some, but tends to be weighed up against other notions of (usually economic) sustainability, limiting the scope for radical re-imaginings of sector-wide change towards events that actively curtail carbon emissions.

Despite conflicting interests over the environmental versus economic sustainability of the festival sector, there are a range of industry-led initiatives to mitigate the environmental impact of music festivals and live events. Indeed, the UK has historically played a leading role in the development of infrastructural support to address the particular environmental challenges facing festivals. UK-based industry organisations such as Julie's Bicycle, Powerful Thinking, and A Greener Festival are all concerned with reducing the carbon footprint of festivals. Outside the UK there are additional organisations across Europe such 
as Energy Efficient (EE) Music, Green Events Europe, and the Green Music Initiative, as well as one-off events (e.g. the Europe Jazz Network's 2015 seminar 'Take the Green Train'). Finally, there are annual summits which have grown steadily in size in recent years where festival promoters gather to share best practice, notably the ADE Green conference in Amsterdam and the Green Events and Innovation conference in London. As such they join a much larger work sector that has emerged in the past two decades to address sustainability issues for global industries of all kinds (a sector now so substantial that it has ironically created an environmental footprint of its own).

Alongside the industry-led work outlined above, there is an emerging body of academic research examining music festivals and environmental sustainability (e.g. Mair and Laing 2010, 2012, 2013; Cummings 2014; Jones 2014); other areas of music production such as recording (Pedelty 2012; Devine 2015); and a broader movement in scholarship aiming to explore the wide-ranging relationships between music, nature, and culture (Rehding 2002; Allen, Titon and von Glahn 2014; Allen and Dawe 2016). Our research can be situated within this growing conversation, but focuses on the case study of music festival communities in Scotland.

\section{Analytical framework and the case study}

Scotland's music festival calendar typically contains approximately 40 recurring events labelled as "festivals" taking place across the country with audience capacities ranging from 300 to 80,000 . Festivals are a significant part of Scotland's musical economy: the total direct and indirect spend generated by music tourism in the region amounts to $£ 280 \mathrm{~m}, 55 \%$ of which is spent on festivals (UK Music 2015, p.26). The largest and most well-known popular music festival in Scotland has historically been T in the Park, which attracts annual audiences of over 80,000 and has run from 1994 to 2016. Interestingly, and for the first time since the festival's inception, the 2017 iteration of T in the Park was cancelled. The promoter, DF Concerts, cited various challenges as reasons for the 
cancellation, but chief among them were environmental issues arising from a site move in 2015:

Against our will, and despite a prolonged fight, we were forced to move from Balado, Kinross in 2015. This move was a mammoth task for the event and one that was compounded by a series of onerous site restrictions placed upon us as preparations for the event in 2015 took place. As the build up to the festival was well underway we were informed by Scottish Government Ministers that we would have to apply for full Planning Permission due to the presence of an unregistered, but protected in law, osprey's nest. The constraints - logistically and financially - that the resulting planning conditions put upon us are simply not workable. ( $T$ in the Park website, 2016).

It is against this backdrop that our research team developed a project entitled 'Fields of Green: Addressing sustainability and climate change through music festival communities,' which ran between April 2015 and September 2016. We drew from a theoretical framework developed by Brennan and Webster (2010) to identify the network of intermediaries that bring together the artist and audience to create a live music event illustrated in the diagram below:

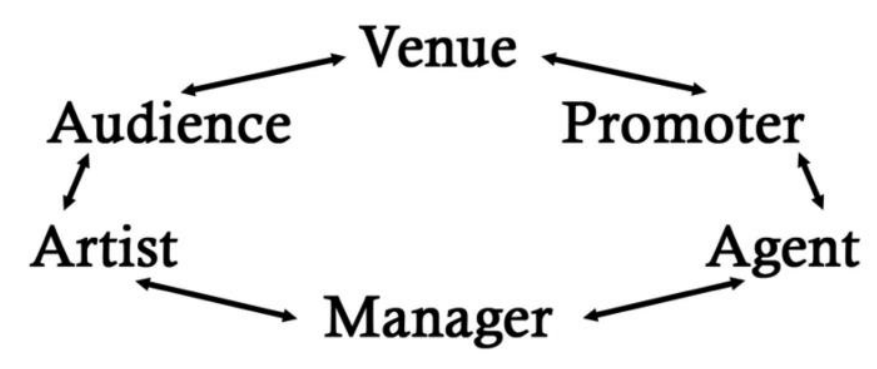

(Brennan and Webster 2010, p.4)

Within this model we wanted to focus on the three stakeholder groups who are generally physically at a music festival in order for it to take place, thus forming a temporary 
community: specifically the audience, artist, and promoter (a category we broadened to "organiser" to include production staff), brought together on the venue site.

We also wanted to go beyond simply understanding how sustainable behaviour change might be enacted within distinct music festival communities. The sustainability behaviour change literature is critical of linear models that assume that simply teaching people about sustainable behaviours will result in their enactment. This ignores the wider context that individuals and groups are embedded within (Owens and Driffel 2008; Shove 2012) or how communities may resist being 'told' to act sustainability (Bell et al. 1996; Heimlich and Ardoin 2008). Taking a systems approach to sustainability in music festivals means understanding complex, interacting behaviour to give a more holistic view of the intermediaries involved. Systems thinking requires bringing together different disciplines to create new knowledges, meanings and relations to enhance action on sustainability (Born and Barry 2008; Ravetz 2000).

We therefore employed a mixed methods approach to understanding and engaging with the different communities identified. We took a co-productive approach and used a combination of social scientific methods and creative practice-led research to enrich our understanding and communication of sustainability (Bell and Pahl 2017). Research has shown that creative practices can help to fill the 'imagination gap' that exists in current approaches to communicating environmental sustainability (Nurmis 2016; Connelly et al. 2016; Galafassi et al. 2018; Tyszczuk and Smith 2018). The project also used a coproduction approach to bridge a gap between academic, industry, and artistic practice by incorporating Creative Carbon Scotland (CCS), the key organisation in Scotland advising arts organisations on issues of environmental sustainability. CCS had traditionally worked with arts organisations funded by Creative Scotland (formerly the Scottish Arts Council), but were keen to extend their reach and engage with the wider Scottish music festival sector (especially the popular and commercial sectors). With this goal in mind, an interdisciplinary 
research team was assembled comprising the four authors of this paper, each coming from a different research background.

\section{Festival Organisers}

The authors adopted a range of methods to develop relationships with live music festival organisers in Scotland. They gathered primary data on the actions being taken to reduce their environmental impacts, and enable and encourage audiences to engage with sustainable behaviours. A particularly important characteristic of the music festival sector in Scotland is the lack of an official umbrella body to coordinate regular meetings or joint working between festivals. We therefore held two scoping roundtable discussions, the first at Xpo North showcase festival in Inverness (June 2015) and the second in Edinburgh with Julie's Bicycle, A Greener Festival and Glastonbury Festival (October 2015); a series of in depth telephone interviews with music festival organisers (January - February 2016), and finally a panel discussion and breakout group held as part of the Wide Days music convention in Edinburgh (April 2016). The interviews sought to establish sustainable actions being undertaken, driving motivations and key challenges for music festivals in Scotland, as well as their willingness to communicate about positive actions being taken and the different responsibilities for artists, festivals organisers and audiences in minimising environmental impacts. Interviews were conducted by telephone with six different music festival organisers, answering a total of eight questions and lasting an average of 30 minutes to an 
hour. Through our discussions and interviews, a series of key themes emerged surrounding actions being taken, and the opportunities and challenges concerning environmental sustainability faced by music festival organisers in Scotland. These were: travel, energy, waste, water and procurement. We will now explore each in turn.

Audience and artist travel is recognised as the single most significant contributor to the environmental impacts of music festivals; audience travel accounts for, on average, $80 \%$ of total festival carbon emissions (Johnston 2015). This parallels Scotland's national figures where transport emissions, including international aviation and shipping, constitute just under a quarter of total emissions, with more than two thirds of these emissions coming from road transport (Scottish Government 2013). In extended interviews we learnt that Scottish festival organisers faced significant challenges in encouraging lower carbon audience and artist travel behaviours, attributing this to the remote locations of festival sites, in combination with poor public transport links and the added expense of contracting private shuttle buses for audience members. Despite this, a number of festival organisers cited positive actions in reducing travel-related emissions including reimbursing artist travel at a public transport rate at Xpo North (Millen, personal interview, 29.01.16), working with local businesses and councils to introduce a Park and Ride system to reduce audience travel directly onto the festival site at The Big Tent Festival (Harrower, personal interview, $25,01.16)$ and running a shuttle bus to cut carbon, despite the financial loss made on the service at Knockengorroch World Ceilidh (Holmes, personal interview, 23.03.16). Martin Jones, representative of the Stornoway-based Hebridean Celtic Festival, also spoke of their work developed over a number of years to rationalise the amount of equipment haulage to the island and minimising the number of lorries travelling to Stornoway (Jones, personal interview, 29.02.16). Learning from England-based festivals with strong green commitments such as Glastonbury Festival, it was evident that the more developed festival network, and higher levels of resource behind large scale festivals, allows for greater connection and bargaining power with public transport providers. Ben Challis from Glastonbury Festival cited successes including the introduction of positive incentives for lower carbon travel choices 
(e.g. prioritising cyclist access to the main festival site and offering additional benefits to including access to solar showers and compost toilets, and discounts on meals). Conversely, he highlighted the challenges posed by the festival's size including reaching maximum capacity for rail travel to the area. He emphasised the importance of Glastonbury's dedicated green initiatives co-ordinator who has a "clear vision and works very hard to make a difference", which is in contrast to the majority of Scotland-based festivals which do not have a dedicated green champion or staff expertise in minimising environmental impacts (Challis, personal interview, 16.10.15).

Onsite energy is second only to travel in the carbon footprint of music festivals (The Show Must Go On 2015). The Powerful Thinking report attributes over-specced and therefore inefficiently run diesel-powered generators as a common contributor to energyrelated emissions (Johnson 2015). A major cause of this is attributed to a "lack of information about requirements and lack of communication" between contractors, festivals, and suppliers (ibid). Similar issues were highlighted in conversations with Scottish festival organisers regarding the need for a community of practice to include not only music festival organisers but suppliers and promoters, who play a significant role in the provision of lower carbon equipment and enabling more joined up thinking across the whole sector. The lack of practical information, as well as resources, to explore alternative energy supplies, was also recognised by festivals including Knockengorroch World Ceilidh (2016) and the Edinburgh Mela festival (2016), as barriers to lower carbon onsite energy generation, despite their interest in exploring such options. Our conversations with festival organisers highlighted the joint need for a reduction in festival site energy demand, as well as new, lower-carbon forms of energy generation.

Waste produced during festival events received a disproportionate amount of attention in our discussions and interviews (especially relative to its associated carbon footprint). However, despite its relatively low environmental impact, it is clear that waste provides an important interface for festival organisers to engage their audiences in sustainable behaviours. As outlined by Chiara Badiali (Julie's Bicycle 2015), the challenges 
around waste produced during festivals range from sewage treatment, to food and packaging waste, and the disposal of low price camping equipment. Furthermore, the media's focus on negative images of waste produced during music festivals in recent years has highlighted the reputational risks associated with this aspect of festival management (e.g. Luckhurst 2014). Both the Edinburgh Mela (2016) and Hebridean Celtic Festival (2016) reported successes in minimising food packaging waste, one of the key areas for waste reduction cited in 'The Show Must Go On' report (2015). This was achieved through the use of a compulsory compostables-only policy for their onsite food suppliers (Edinburgh Mela) and the introduction of branded beer cups, distributed through a deposit system (Hebridean Celtic Festival). The addressing of waste reduction by Scottish festivals sits against the backdrop of the Scottish Government's 'Zero Waste regulations' (2014) which place an obligation on all commercial and public bodies to separate key materials including plastic, glass, metals, paper and card for recycling, with fines for failure to comply. We observed a mixture of personal, ethical drivers, bottom-up reputational pressure, and top-down governance incentives as playing a role in how music festivals engaged with waste management and reduction practices.

Similar regulatory drivers applied to Scottish and UK music festivals' engagement with water management, through required compliance with environmental protection laws (UK Government 2003). Glastonbury Festival cited their 'Green Police' initiative introduced to prevent audience members' pollution of the water and hedgerows, with the risk of urine entering the local water table being a significant issue for the festival (2015). Similarly, T in the Park referenced the protection of the river on site from waste-water produced during the festival as a major component of their sustainability efforts (2016). The role of regulation and licensing laws is particularly worth noting here as a structural level intervention which can stand to counter the economic imperatives of festivals, therefore playing an important part in changing behaviours. Powerful Thinking have highlighted that although the direct carbon emissions associated with water consumption during UK music festivals are negligible when compared to energy and waste, there are wider impacts to consider including the prevalence 
of water consumption via plastic bottles and the rise in droughts in recent years which have resulted in water increasingly being sought from further afield (Johnson 2015). Bristol Festival Forum's (2015) report takes a similar approach to understanding supply chain and transportation impacts, revealing that the main environmental impact associated with temporary toilets originates in the transportation of human waste by road, i.e. CO2 emissions from diesel engines in waste tankers, and the movement of the toilet cubicles themselves, rather than water consumed.

Festivals organisers also expressed the importance of procurement and their relationships with their surrounding communities with regard to encouraging sustainable practices. A number of festivals (Howlin' Fling, Hebridean Celtic Festival and T in the Park) highlighted their significant efforts to work with local food and drink suppliers, citing not only the reduced impacts associated with seasonal produce and lower travel miles, but also the wider social and economic benefits brought to the communities they inhabit or with whom they share their festival sites (2016). Furthermore, The Big Tent embraced the educational potential of their festival as a site for the convergence of alternative thinking about food and sustainability, supporting the upscaling of particular caterers' services and the development of the Fife Diet food movement, which continued to have implications for the sustainable food debate in Scotland after the festival finished (Devine 2014). These examples can be paralleled with significant decisions by UK festivals to address food-related carbon emissions and encourage lower impact audience behaviours, including Shambala Festival's decision to remove meat and fish from their on-site catering offering in 2016. Despite these positive examples, the enduring 'disposable culture' associated with music festivals still needs to be addressed, requiring collective buy in and effort from suppliers, organisations and audiences (O’Neill, personal interview, 16.10.15).

Many music festivals are already taking a proactive approach to improve the sustainability of their events with some, such as Shambala, doing so out of ethical beliefs, whilst others, such as T in the Park, are motivated at least in part by corporate social responsibility. However, the extent to which such efforts will result in tangible change is 
ultimately dependent upon a range of factors: for example, the supply chain being developed enough to supply sustainable festival technologies and, how amenable festival audiences are to adopting sustainable behaviours. Indeed, some may even actively resist the imposition (Mair and Jago 2010). In Scotland, a range of preventative barriers for festival organisers were identified including: a lack of technical expertise concerning the adoption of low carbon-energy technologies, poor public transport provision in remote locations, and a lack of resources to minimise festival impacts. Despite this, organisers displayed a range of motivating factors for addressing environmental sustainability, including: their personal, ethical ethos, positive relationships with communities in which festivals take place, financial savings from local sourcing of products and services, and compliance with regulatory requirements. In our discussions with festival organisers we concluded that a network to support the sharing of best practice examples, resources and advocacy efforts, would benefit the sector as a whole. The effectiveness of this would be greatly enhanced through the involvement of additional parties such as local authorities, the Scottish Environment Protection Agency, Transport Scotland, as well as programmers, musicians and audiences to establish how they can work better together.

\section{Festival Audiences}

The everyday domestic routines of audiences are inevitably disrupted through attending a music festival. Along with the novelty of being in a festival setting comes new choices about how to behave, each with different environmental consequences. Festivals have the risk of becoming "responsibility holidays" for audiences: individuals can broadly support proenvironmental behaviours at home, but are less likely to give up lifestyle choices such as air travel when on holiday, for instance, or when undertaking leisure activities more generally (Barr et al. 2010; Holden and Linnerud 2010). Consequently, this section turns towards 
understanding the extent to which festival audiences undertook sustainable actions within the context of attending music festivals.

Two festival sites in Scotland were chosen for further exploration. Both could be categorised as 'small-to-medium' in terms of the number of attendees. The first, lasting for two days, was a multi-site urban festival which combined talks and performances with networking activities for musicians. The second was a greenfield site, located three miles from the nearest urban settlement which included a range of creative activities along with musical performances over three days. The urban site mainly attracted an adult audience, whilst the greenfield site had a broader audience including families with young children. There are two reasons why these festivals were selected for study. First, both are long standing, recurring, comparably sized events in the Scottish festival calendar, therefore allowing for possible comparative follow up studies. Second, the Scottish festival sector can be roughly divided between greenfield weekend camping festivals and urban multi-site events, and therefore studying one of each kind allowed for the possibility of making potential comparisons about the environmental challenges faced in these two very different types of setting.

Given the availability of resources, a mixed methods approach was adopted. Observations of both sites took account of environmental sustainability information, the location of recycling bins, and how audiences actively engaged or not with the proenvironmental provisions. In addition, a face-to-face survey was developed for festival attendees in order to reach a greater number of participants than interviews alone. The survey contained thirty quantitative and qualitative questions in order to understand proenvironmental actions when at a music festival across three behavioural areas (travel, food, accommodation) and the extent to which their actions differed in the domain of a music festival compared to the domestic sphere. A short form of the survey, consisting of 7 questions, was developed in order to raise the response rate amongst respondents who were pressed for time. In total, there were 135 respondents to the survey ( 89 from the greenfield site - most of whom answered a long form version of the survey - and 46 from the 
urban festival). Convenience sampling was used to select potential respondents and, whilst this is not representative of the general population, allowed for an initial exploration of the topic (Henry 1990).

The observations showed that activities on the urban festival site took place across six main venues, with a further seven venues enrolled for a wider evening music programme. The urban location of the site meant that there were many constraints on the festival organiser for encouraging sustainable production practices since it relied on existing venues, with little to no control over the infrastructure supporting each venue. Wandering between each of the sites, it was clear that the higher number of revellers overwhelmed the capacity of the existing bin system, for example, with evidence of the overfilling of bins. None of the venues provided any form of recycling. In addition, the provision of foodstuffs was dependent on the pre-existence of cafes, bars and restaurants whilst most attendees resided at existing hotels which may or may not have had an environmental policy.

Activities on the greenfield site took place over two main areas, with the addition of an attached campsite. The festival had an environmental policy and discouraged audiences from bringing certain materials onto site (e.g. glass). A lift-share forum was provided and buses were available for attendees from urban areas. Service providers at the greenfield site were mainly local and included a 'food ambulance' where food from supermarkets was reused to provide meals. Patrons simply had to pay what they thought the meal was worth (Figure 1). 


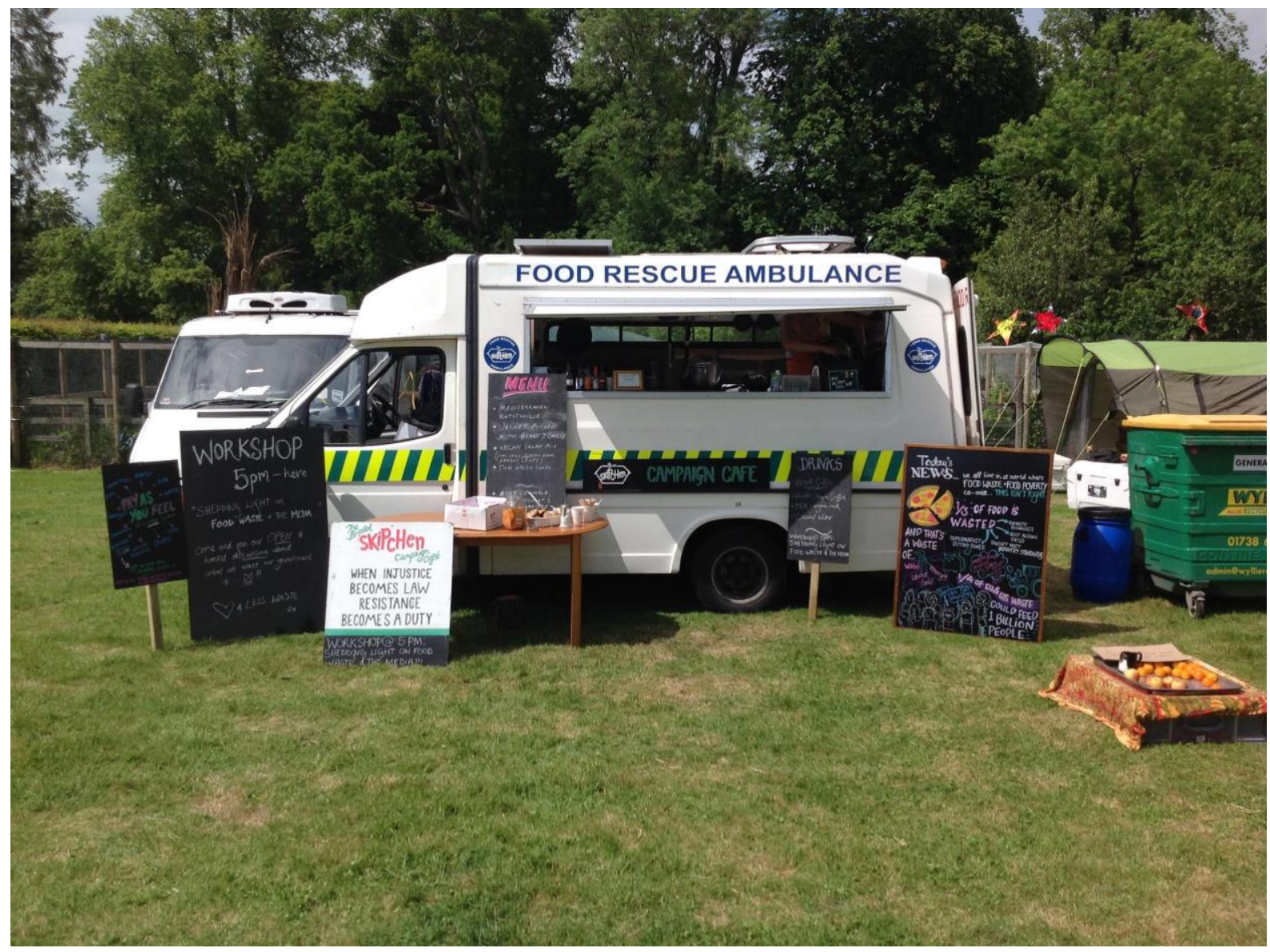

Figure 1. Food Rescue Ambulance to reuse waste produce. Source: Authors, 2015.

Recycling bins were provided, but these were spatially located on the margins of the site and were the same colour as the general waste bins, making them less identifiable. Not only could the bins be easily ignored by attendees, but the colouring ran counter to conventional UK practice which distinguishes recycling bin content by colour. As time passed at the greenfield site, cross-contamination of the bins was evident. In addition, the provision of biodegradable plastic drink cups proved to be counter-intuitive. Such cups are supposed to be disposed of with landfill waste, but many were evident in the plastic recycling bins.

In terms of the survey data, there was an even gender split. Most attendees were between the ages of 25 and 44 . Whilst a high proportion of festival attendees were students, almost fifty per cent indicated that they were in full time work which suggests a higher disposable income. 
Previous research estimates that audience travel accounts for 80 per cent of the total emissions for an average festival (Johnson 2015, p.2). How people get to and from a festival is therefore an important issue in terms of addressing pro-environmental actions and reducing festival carbon emissions. As Figure 2 shows the majority of those travelling to both urban and greenfield sites were in a private vehicle or van. However, there were some subtle differences: the urban festival had a higher proportion of audience members travelling by public transport. This is presumably due to the urban area being furnished with a wellconnected train station.

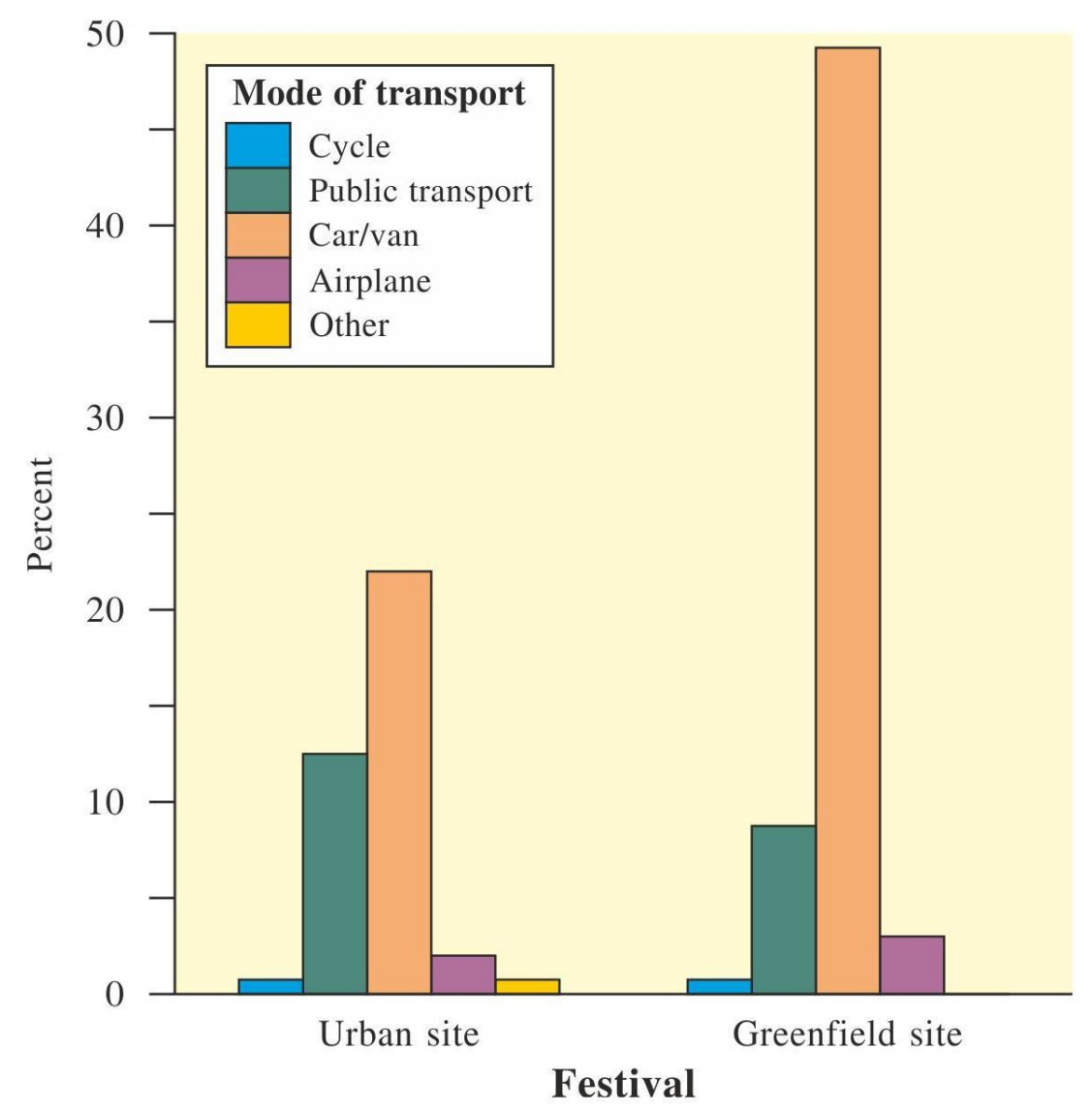

Figure 2: Main mode of transport for each case study site. Number of respondents: 135.

The longer the distance travelled, the more likely that respondents used public transport (Figure 3). These results are broadly similar to other modal surveys where people 
eschewed very long drives (RAC 2014). In addition, respondents typically came from urban areas - almost two-thirds of respondents came from a large urban area (mainly Glasgow or Edinburgh). Just over 50 per cent of respondents travelled alone or with one other person which suggests significant scope for increasing lift-sharing between festival-goers.

Qualitative responses that investigated why indicated that people were carrying equipment (particularly musicians). Those who travelled by public transport included one respondent who 'wanted to drink alcohol'. Figure 4 shows the main reason why respondents chose their mode of travel. On the whole people preferred private vehicle travel in terms of speed and convenience or when they had camping or other equipment to carry. As previously noted, people were more likely to take public transport over long distances, and five respondents cited environmental reasons to explain this choice. Other qualitative responses indicated a wish for the utmost comfort when travelling, or that they wanted to travel with friends or relatives.

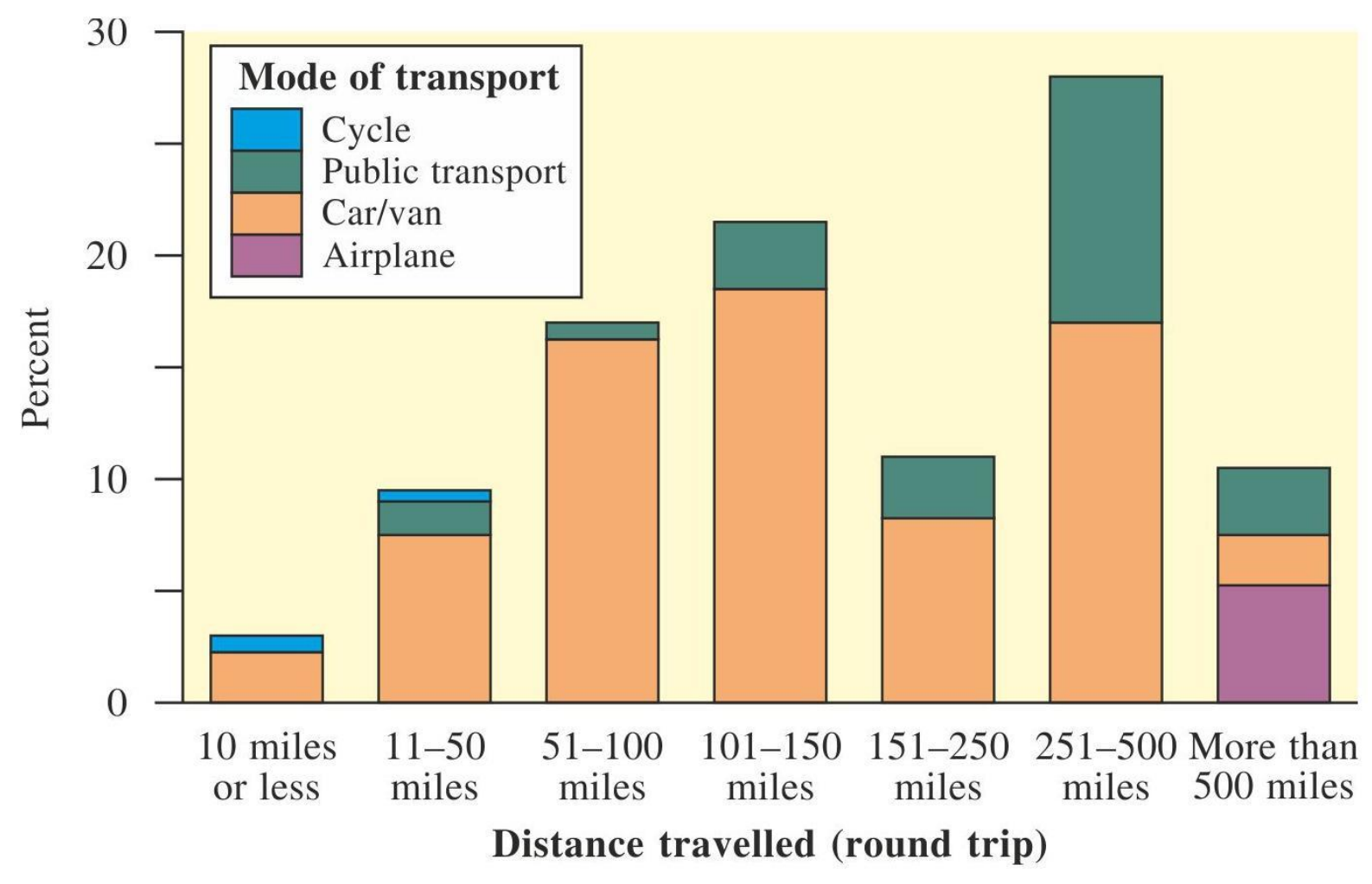


Figure 3: Mode of transport versus the amount of miles travelled in a round trip. Number of respondents: 135 


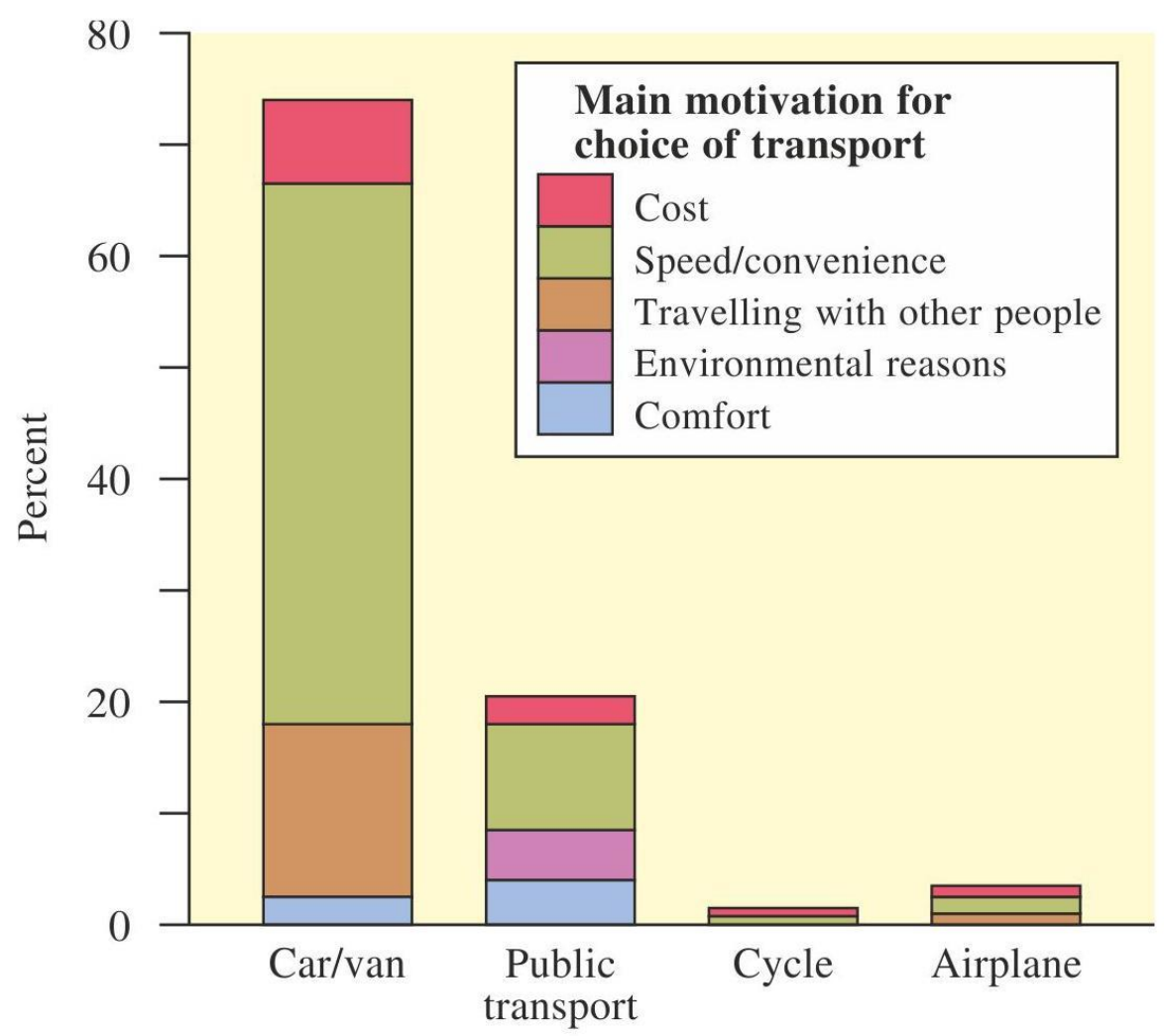

Main mode of transport

Figure 4: Reason for selecting main mode of transport, by transport type. Respondent Number: 135

As mentioned earlier, many of the greenfield festival respondents completed a longer form version of the survey, which allowed us to ask additional questions about differences in audience behaviour between domestic and festival domains. Table 1 outlines the results across six pro-environmental areas: energy conservation, water conservation, sustainable food, recycling waste, reducing waste and sustainable travel. For most areas, there was a fairly even split between 'no difference' or 'more often at home'. The conservation of water, however, demonstrated that festivals do not always hinder pro-environmental behaviour. This was particularly stark at the greenfield site, where there was a lack of shower facilities. 
Table 1: Self-assessed difference between environmental behaviours at home and environmental behaviours at a festival. Respondent Number: $88^{2}$

\begin{tabular}{|l|c|c|c|}
\hline & More often at home & No difference & More often at a \\
& $(\%[\mathrm{~N}])$ & $(\%[\mathrm{~N}])$ & festival \\
$(\%[\mathrm{~N}])$
\end{tabular}

The results here point to the issue of control over pro-environmental actions.

Qualitative answers indicated that respondents felt that they had little control, particularly in terms of conserving water. One respondent indicated that pro-environmental behaviour was a routine dependent on known systems and, therefore, taken out of context hindered their ability to act the same way as he/she would have done at home: 'I'm in control of energy and water that I use at home'. Others indicated that they viewed the music festival in a similar way to a holiday: 'In all instances, I have gotten used to approaching festivals with a sort of 'weekend away' mentality, meaning that I don't always live to my means'. This does not necessarily mean that all environmental actions are dispensed with; rather, as one

\footnotetext{
${ }^{2}$ Note that 86 of 89 respondents at the greenfield festival completed the long form survey.
} 
respondent commented 'I tend to try and be environmentally friendly in everyday life and see a festival as a break in general - not that I stop caring, I'm more likely to indulge.'

The long form questionnaire also asked who audiences thought should be responsible for ensuring that a music festival was as environmentally sustainable as possible. Respondents were given a choice of six different actors (with potential 'other' and 'don't know' answers) and could choose more than one option. Table 2 shows the percentages for each type of actor. Virtually all respondents indicated that festival organisers were responsible for this aspect, while four-fifths indicated that individual audience members were also responsible. The responses to this question emphasise that there is a perceived shared responsibility for encouraging pro-environmental actions within the context of the music festival, and also links to the need for festival organisers to assume a pivotal role in directing actions.

Table 2: Responses to the question: 'Who is responsible for ensuring that festivals are environmentally sustainable?' Respondent Number: 86)

\begin{tabular}{|l|c|}
\hline & $\begin{array}{c}\text { Proportion of respondents } \\
\text { selecting this option (valid \%) }\end{array}$ \\
\hline Festival Organisers & 97.7 \\
\hline Yourself & \\
\hline The National Government & 81 \\
\hline Devolved Government & 20.7 \\
\hline
\end{tabular}




\begin{tabular}{|l|c|}
\hline & \\
\hline Local Authority & 51.8 \\
\hline Those Providing Services & 63 \\
\hline Don't Know & \\
\hline
\end{tabular}

Both the observational work and the surveys reveal that more can be done to make pro-environmental behaviour the default for audiences. In our case studies, audiences, whilst concurring that they have responsibility for pro-environmental behaviour, nevertheless suggest that material limitations inhibit their ability to act sustainably. Changes on the side of festival infrastructure will not work on their own, but neither will behavioural change campaigns targeted at audiences. Instead, we can think of a music festival as a sociotechnical network where different actors have diverging concerns and priorities, and both sides need to be taken into account (Chilvers and Longhurst 2016). Thus, any transition towards sustainable audience practices at music festivals needs to recognise how audience behaviour co-evolves with supporting technological infrastructure.

\section{Festival Artists}

Whereas festival organisers see the festival as the culmination of a year's work centred around one event, and where audiences see the festival as a one-off leisure activity at which they spend a short period of concentrated time, artists look at festivals as merely one stop on a larger touring itinerary and linger on site for less time. This means that out of the three 
examined types of festival stakeholder, artists represent the group that has the most transient relationship with any given festival.

Travel - particularly artist and crew movement between festival performances - has been identified as one of the least well understood or researched environmental impacts associated with music festivals, despite its large effect (Johnson 2015). As such, we focused our research with festival artists on exploring the impact of their travel movements across the festival season.

Firstly, the environmental impact of artist travel was investigated. Most artists have a complex touring schedule that includes attendance at music festivals amongst other types of engagement. This may make their travel to and from a music festival even more carbon intensive and, consequently, the musicians were asked to track their movements to and from all live performances to capture the wider context within which they work and travel. For this purpose Jo Collinson Scott (who writes and performs professionally under the stage name Jo Mango) joined four other internationally recognised Scottish songwriter-performers - Louis Abbott (of the band Admiral Fallow), Rachel Sermanni, Johnny Lynch (performing as Pictish Trail), and RM Hubbert - in documenting their travel to live performances across the 2015 festival season (counted as April to September that year). All of these artists regularly play across a range of Scottish festivals as well as others in Europe and North America and are signed to local independent Scottish record labels or are self-releasing as solo artists. All work as full-time professional musicians (with the exception of Collinson Scott who is also employed as an academic). Their touring, although international, is generally relatively smallscale and self-managed.

Using Creative Carbon Scotland's 'claimexpenses.com' carbon tracking tool, the five artists were shown to collectively cover 118,000 passenger miles and generate $19,314 \mathrm{~kg}$ of $\mathrm{CO} 2$ emissions across the season. Most of the travel was carried out by car or van, and when mapped, can be seen to be repetitive and inefficient, belying the vocabulary of a gig 'circuit' (Lashua and Cohen 2010). As an example of this, the travel activities of two of the musicians can be seen visually represented on maps in Figures 5 and 6 below. For smaller 
artists (and particularly self-managed or agentless independent artists) the web of appearances within which festival performances sit is often fragmented and/or hand-tomouth and therefore far-sighted planning is difficult (Julie's Bicycle 2010). The need to react to demand from specific audiences means that inefficiencies in routing are commonplace and there is no way to rationalise itineraries. Smaller artists often don't have the level of influence that would be required to move venues or agents into providing more costly environmentally friendly touring options.

The effect of these pressures on the artists involved in the project was demonstrated when the artists were presented with the maps of their travel. At a festival performance marking the end of the project in January 2016, the artists publicly discussed their conflicted feelings about the results. The maps that represented larger amounts of travel prompted the participating artists to express guilt about the environmental impact of their behaviour.

Conversely, where the maps showed less travel, the artists expressed feelings of failure as more travel was perceived to represent greater audience reach, income and social capital. This discussion highlighted some of the complex and often contradictory feelings and behaviours surrounding the musicians' role in contributing to the environmental impact of festivals. 


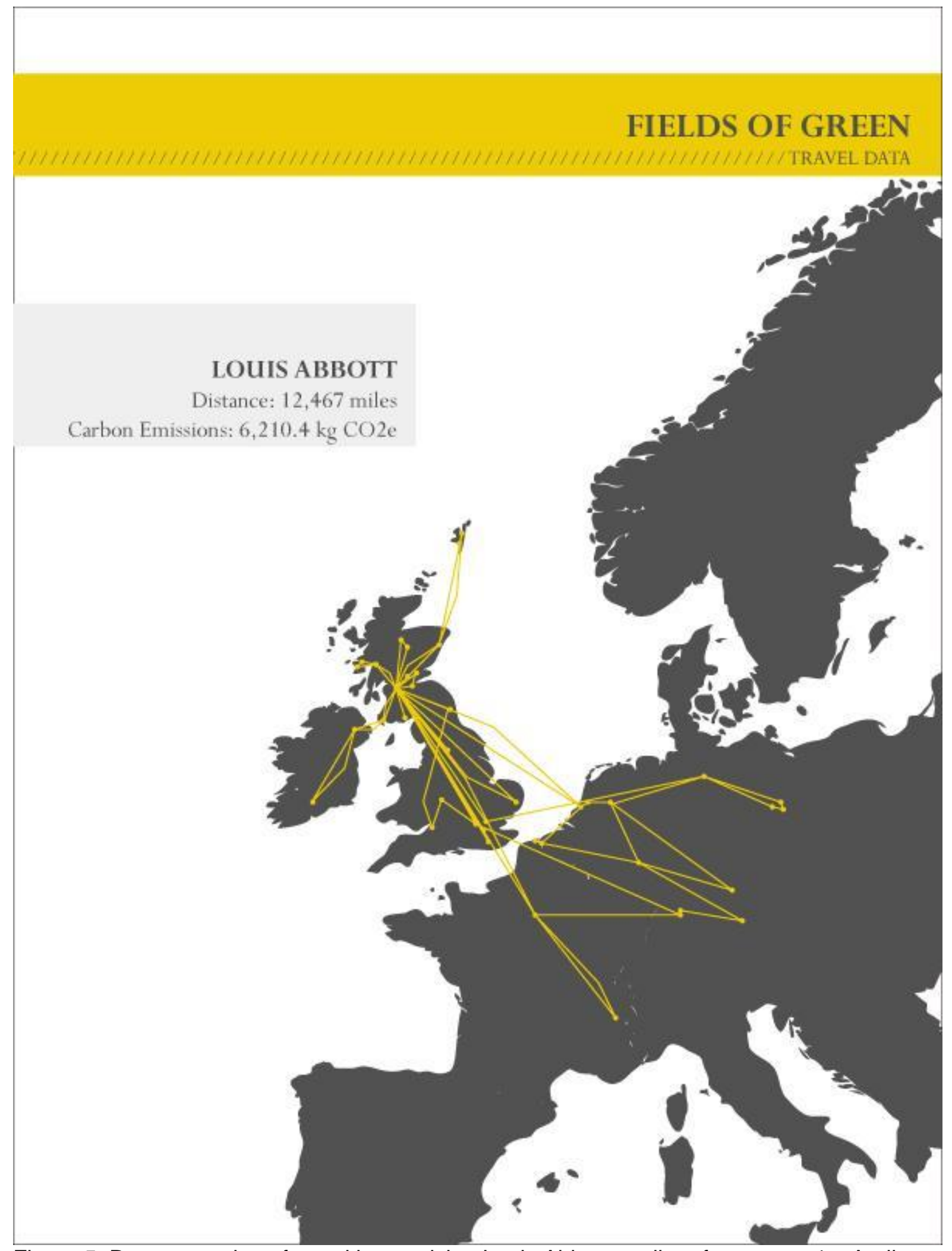

Figure 5: Representation of travel by musician Louis Abbott to all performances 1st April -

30th September 2015 (distance travelled approximated in miles rather than passenger miles). Image by Helen Kellock. 


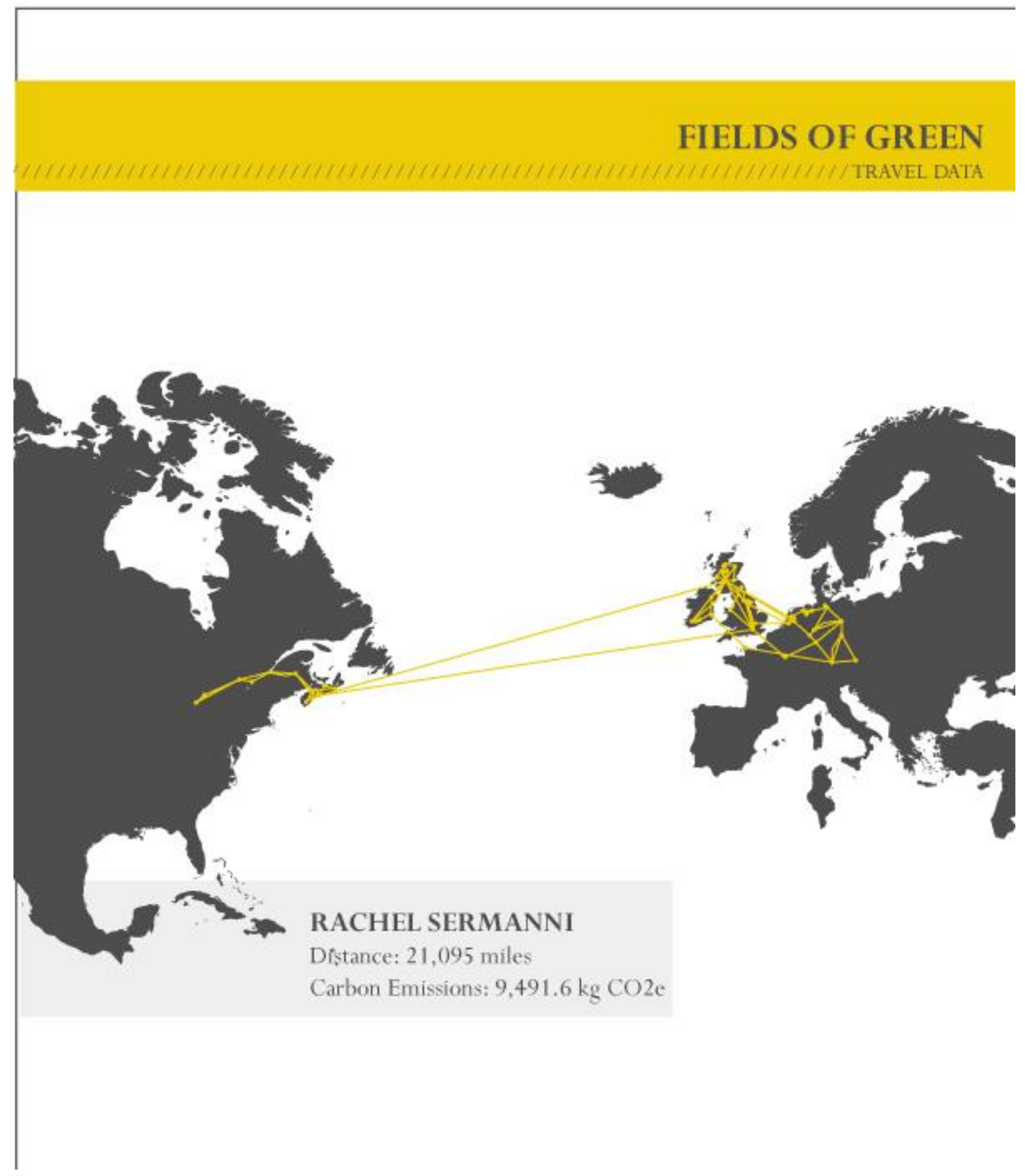

Figure 6: Representation of all forms of travel by musician Rachel Sermanni to all performances 1st April - 30th September 2015 (distance travelled approximated in miles rather than passenger miles). Image by Helen Kellock. 
As has been previously outlined, the role of the music performed for and within music festival communities can be seen to be of crucial importance in investigating, understanding and articulating issues related to sustainability and climate change. There are four key argumentsfor music's role in contributing tobehaviour change that are relevant here: music's ability to communicate and exemplify complexity (Eisner 1997; Kagan and Kirchberg 2016; Knowles and Cole 2008; Sandri 2013); its potential for emotional engagement (Kagan and Kirchberg 2016; Mark 2016; Pedelty 2012; Takach 2016; Zammit-Lucia 2013); its capacity to reach wide and diverse audiences beyond those interested in academic studies (Walsh, Rutherford and Crough 2013); and its creation of a space for dialogue, offering opportunities for resistance to social conditioning and the imagination of alternative spaces (Grossberg 1993, Lipsitz 1994, Pratt 1994). Similarly, Mark Pedelty describes three functions of popular music towards encouraging behaviour change and sustainable actions: (1) communication: music as a means of mediating environmental matters; (2) art: music as creative, aesthetic, symbolic and affective expression of environmental meanings; and (3) advocacy: music as an attempt to inform, inspire and persuade audiences (p.7). As such, a second perspective on artist travel to festivals was drawn out through the use of practice-led research.

The method for the practice-led research component was inspired by a model established by Robin Nelson (2013), and involved the creation of five songs written collaboratively between each musician and the researcher (Jo Mango). The musicians were asked to use songwriting to respond to and make sense of their own role with relation to the environmental sustainability of music festivals, focusing on their travel behaviours. Five songs were completed for a live premiere in front of an audience of approximately 200 at Celtic Connections festival in January 2016. The songs were also recorded and the resulting EP - Wrack Lines - was released by Scottish record label, Olive Grove Records, with proceeds going to the charity Creative Carbon Scotland. Designer Helen Kellock used the 
abstract shapes created by the mapping of musicians' travel to inspire the development of the artwork of the EP and visuals for the festival performance (Figure 7).

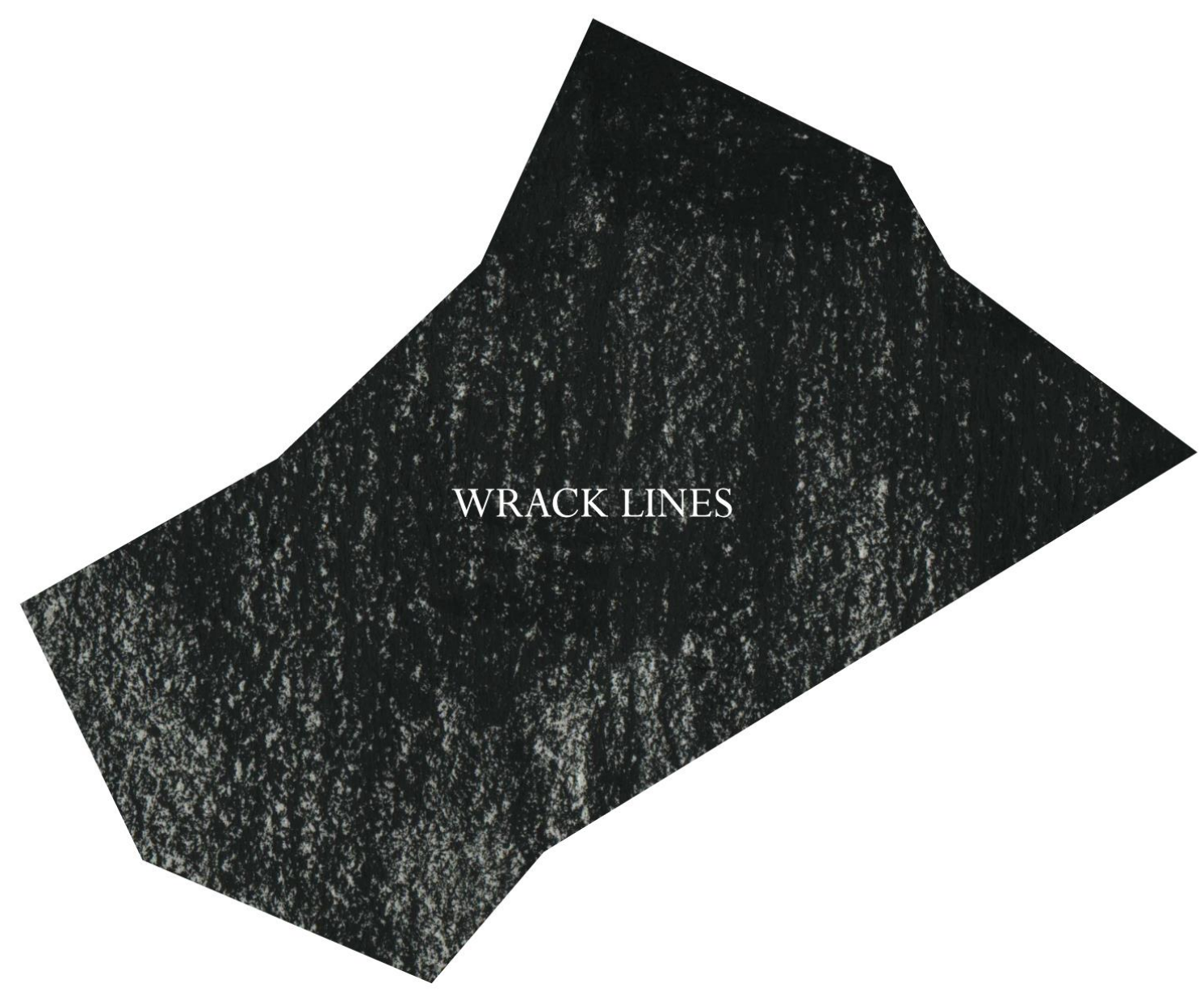

Jo Mango \& Friends

Figure 7: Wrack Lines EP artwork. Image by Helen Kellock.

The songs premiered at the festival, which can be listened to online ${ }^{3}$, make audible a number of key tensions around festivals and sustainable behaviours. Firstly, the contradiction between the representation of music festivals as a place outside of the

\footnotetext{
${ }^{3}$ Songs are available at https://soundcloud.com/olivegrove/sets/wrack-lines
} 
everyday routine where ideals of environmental sustainability can be more easily enacted and the reality of the evidence of the environmental impact of travelling to festivals is keenly felt by the musicians. Secondly, the idea of the music festival engendering feelings of belonging and 'communitas' or as a 'garden' to return to is contrasted with stark expression of feelings of loneliness and personal struggle from musicians who identify the rootlessness of constant movement between festival (and other) sites as a personally unsustainable aspect of their working lives. Finally, a number of the songs feature the exploration of a tension that is felt between environmental sustainability on the one hand and cultural and economic sustainability on the other.

For example, thematic explorations in a number of the songs demonstrate the artists' awareness that performances at festivals (among other live appearances) are becoming increasingly important in terms of generating income from their music. But there is also awareness of the environmental impact associated with this change. Pictish Trail, in his song for the project, 'Believe Me, I Know' explicitly explores the economic function of personal scarcity in his work with the following lyrics, where he imagines a compere introducing a performance at a far flung site:

\footnotetext{
"All the way from Scotland" the man said

And I ate up the magic that the 20,000 miles made

I played the "rare" thing

The canapéd rich people craved
}

There is a consistent focus in the songs on a sense of guilt about such need for travel, which is tempered with discussion of offsetting possibilities: with standard carbon-offsetting behaviours, or the positive good of creating music that might help generate dialogue about important political matters and/or enable living well amongst audience communities. How does an artist weigh up whether to take up the invitation to travel a large distance to perform to an audience of 30 ? If artists were to tackle important environmental issues with their 
music, would that make the travel worth the cost, or would the seeming hypocrisy of their behaviours undercut that? The same song also wrestles with this theme when the singer asks himself:

Am I so selfish as to write a song

That keeps me

Strapped in the backseat

For 5 hours or longer?

Playing to literally tens of people

Collected together

Just to cover

My transport home?

He then concludes that he is aware of the difficulty involved in this behaviour and the seesaw action of trying to balance it out in various ways, stating, "believe me, I know, I see-saw what l've done'. Where the amount of travel required of musicians across performances between festival sites is viewed by them as environmentally unsustainable, it is also portrayed as personally unsustainable and fraught with loneliness and personal difficulty (Scott and Scott 2017). This is in contrast to the perception of the musician and their music at the locus of an alternative community of belonging on the festival site.The song 'Bitter Fruit', written in collaboration with Rachel Sermanni, exemplifies such concerns in its indisputably weary tone. The lyrics turn the focus on to the interconnectedness between the wellbeing of a performer and the wellbeing of the planet, with each A-section returning to the changing refrain, "Oh world, how did we get so... tired/hungry/thirsty?" The songwriting practice here thus foregrounds a perceived interconnectedness of environmental, economic and physical/mental sustainability of musical practice.

The collaboration with Louis Abbott, entitled 'Loneliness and Rhythm', also explores the off-kilter rhythms of life that such travel creates in an artist, and the seeming 
unsustainability of such an existence. The time signature constantly shifts between 5/4, 7/4 and 3/4 time creating an unsettling, unbalanced rhythm to the piano accompaniment, and an unusual flow to the melody in the context of the genre. This is an aural representation of the title of the piece, which summed up for the artists the key themes of the experience of travelling to performances (i.e. the difficulties of sustaining balance). The final line of the chorus points to the second of the key themes that Wrack Lines presents, as it describes the juxtaposition of the, 'ephemeral and concrete'. This is a reference to the idea of offsetting or attempting to quantify the fleeting benefits of festival performance against the very concrete costs of that travel as measured in carbon emissions. It is clear then, that the musicians are acutely aware of these concrete costs and are seeking in their musical work here to weigh up these complex considerations and their emotional outworkings.

\section{Conclusion}

Based on the outcomes of the Fields of Green project, we recommend five avenues through which to develop this work further. First, the existence of a support network is crucial for small to medium independent music festivals to build capacity in successfully addressing environmental sustainability. In the case of Scotland, we found through our interviews and focus groups that the lack of a pre-established network hindered the development of a community of practice among music festival organisers to share ideas, skills and expertise. Festival organisers may wish to improve the sustainability of their event, but many of themparticularly at the grassroots level, are limited by their capacity to resource staff time and additional costs associated with equipment. Both technical expertise required in certain areas (e.g. efficient generator practices, alternative energy supply options) and leverage to bid for low carbon equipment procurement (via collective organisation when negotiating with suppliers) are areas for attention. 
Second, engagement with local authorities and planners (which have historically tended to focus on the noise produced by festivals rather than their environmental impact) could potentially drive action. Scotland has relatively progressive policies on both planning for climate change and reducing waste, and these could be deployed more comprehensively with productive dialogue between organisers and local authorities.

Third, there is an important role for the creation and dissemination of music within festival communities that makes audible the tensions between economic or cultural sustainability, and environmental sustainability. Work such as this may engage diverse audiences on an affective level in difficult dialogues. There is excellent potential to expand the work of artist-led creative practice to engage not only musicians themselves but also audiences and organisers - work that could be achieved through our fourth recommendation: to connect the legacy of the Fields of Green with wider initiatives exploring the relationship between culture and environmental sustainability. (In the case of Scotland this would include the culture/SHIFT programme run by Creative Carbon Scotland and the Climate Conversations programme endorsed by Scottish Government, but there are likely to be analogous initiatives in other regions and nations as well). Music festivals, if not fully fledged communities in and of themselves, nevertheless act as hubs to connect otherwise disparate communities, and as such can be used to foreground, link, and progress sustainabilityrelated issues between individuals (artists and audiences), organisations (festival organisers, production suppliers, local authorities), and infrastructure (driven by policymakers and investors).

Finally, our research showed that when it comes to music festivals and environmental sustainability, onsite waste - because of its visibility in media and at a festival itself - tends to be a focal point despite the fact that energy and travel are far greater contributors to a festival's overall carbon emissions. More research needs to be conducted in this area, particularly around the issue of taking a systems-level approach to addressing the environmental impacts of in energy use and travel among organisers and suppliers, musicians, and audiences. 
Our project deliberately brought together a range of methods and disciplinary perspectives in order to examine the issues of environmental sustainability at music festivals. Instead of siloing constrasting methods (does such research belong in the field of popular music studies, ecomusicology, or event management?), we conclude that in order to truly address the complexity associated with moving towards a more environmentally sustainable culture, it is in fact imperative to employ approaches which foster new connections between different disciplines, or in the case of music festivals, between the different actors and agendas in music festival communities.. 


\section{References}

Allen, A., \& Dawe, K (eds). 2016. Current Directions in Ecomusicology: Music, Nature, and Environment (New York, Routledge)

Allen, A.S., J.T. Titon and Von Glahn, D. 2014. 'Sustainability and Sound: Ecomusicology Inside and Outside the University', Music and Politics, 8(2), pp.1-26

Anderson, B., 2002. A Principle of Hope: Recorded Music, Listening Practices and the Immanence of Utopia. Geografiska Annaler. Series B, Human Geography 84, pp. 211-227.

Anderton, C. 2015. 'Branding, sponsorship and the music festival', In The Pop Festival, ed.

G. McKay (London, Bloomsbury Academic), pp.199-212

Arts and Humanities Research Council. 2015. Public Policy Highlight Notice in the AHRC Leadership Fellows Scheme (Swindon, AHRC)

Barr, S., Shaw, G., Coles, T., and Prillwitz, J., 2010. 'A holiday is a holiday: practicing sustainability, home and away', Journal of Transport Geography, 18, pp.474-481

Barrett, E., and Bolt, B. 2012. Practice as research: approaches to creative arts inquiry (London, I.B. Taurus) 
Bottrill, C., Lye, G., Boykoff, M., and Liverman, D. 2008. First Steps: UK Music Industry Greenhouse Gas Emissions for 2007 (Oxford: Julie's Bicycle)

Brennan, M. and Webster, E. 2010a. The UK Festival Market Report (London, UK Festival Awards)

Brennan, M. and Webster, E. 2010b. Why Concert Promoters Matter. Scottish Music Review 2(1), pp.1-25.

Chilvers, J. and Longhurst, N. 2016. Participation in Transition(s): Reconceiving Public Engagements in Energy Transitions as Co-Produced, Emergent and Diverse. Journal of Environmental Policy \& Planning 18(5), pp.585-607

Clarke, M. 1982. The Politics of Pop Festivals (London, Junction Books)

Cummings, J. 2014. 'The greening of the music festival scene : an exploration of sustainable practices and their influence on youth culture' In The Festivalization of Culture, ed. A.

Bennett, J. Taylor, \& I. Woodward, pp. 169-186

Devine, C, 2014. 'What next for the Fife Diet's Mike Small?', The Sunday Herald, 7 February 2014 http://www.heraldscotland.com/arts_ents/13144581.What_next_for_the_Fife_Diet_s_Mike_S mall/ 
Devine, K. 2015. 'Decomposed: a political ecology of music', Popular Music, 34, pp.367-389

Eisner, E.W. 1997. 'The promise and perils of alternative forms of representation', Educational Researcher, 26(6), pp.4-10

Grossberg, L. 1993. 'The framing of rock: Rock and the new Conservatism', In Rock and Popular Music: Politics, Policies, Institutions, eds. T. Bennett, S. Frith, L. Grossbeg, J. Shepherd \& G. Turner (London, Routledge) pp.193-208

Hargreaves, T. 2011. 'Practice-ing behaviour change: Applying social practice theory to proenvironmental behaviour change', Journal of Consumer Culture, 11, pp.79-99

Hawkes, J. 2002. “Creative Engagement.” Artwork Magazine, 54, pp.10-15

Henry, G.T. 1990. Practical Sampling. (London, SAGE)

Holden, E., and Linnerud, K. 2010. 'Environmental attitudes and household consumption: an ambiguous relationship', International Journal of Sustainable Development, 13, pp.217-231

Johnson, C. 2015. The Show Must Go On: Environmental Impact Report and Vision for the UK Festival Industry (London, Powerful Thinking)

Jones, M. 2014. Sustainable Event Management (London, Routledge)

Kagan, S. \& Kirchberg, V. 2016. 'Music and sustainability: organisational cultures towards creative resilience - A review', Journal of Cleaner Production, 135, pp.1487-1502 
Knowles, G.J. \& Promislow, S. 2008. 'Using an arts methodology to create a thesis or dissertation', In Handbook of the Arts in Qualitative Research, eds. J.G. Knowles \& A.L. Cole (Thousand Oaks: Sage), pp.55-70.

Lashua, B. \& Cohen, S. 2010. 'Liverpool musicscapes: Music performance, movement and the built urban environment', In mobile Methodologies, eds. B. Fincham, M. McGuinness, L. Murray (London: Palgrave Macmillan), pp. 71-84.

Lipsitz, G. 1994. Dangerous Crossroads: Popular Music, Postmodernism and the Poetics of Place (New York, Verso)

Luckhurst, K. 2014. 'Tens of thousands of tents are discarded at festivals - and I know why', The Guardian, 13 June: https://www.theguardian.com/theobserver/shesaid/2014/jun/13/tens-of-thousands-of-tents-are-discarded-at-festivals-and-i-know-why

McDonald, C. 2016. 'Tori Amos as shaman', In The Cambridge Companion to the SingerSongwriter, eds. K. Williams \& J. Williams (Cambridge, Cambridge University Press), pp.238-245

Mair, J., and Jago, L. 2010. 'The development of a conceptual model of greening in the business events tourism sector', Journal of Sustainable Tourism, 18, pp.77-94

Mair, J. and Laing, J. 2012. 'The greening of music festivals: motivations, barriers and outcomes. Applying the Mair and Jago model', Journal Of Sustainable Tourism, 20(5), pp.683-700 
Mair, J. and Laing, J. 2013. 'Encouraging pro-environmental behaviour: the role of sustainability-focused events', Journal of Sustainable Tourism, 21(8), pp.1113-1128 McKay, G. (ed.) 2015. The Pop Festival (London, Bloomsbury)

Mark, A. 2016. 'Don't organise, mourn: Environmental loss and musicking', Ethics and the Environment, 21(2), pp.51-77

Nelson, R. 2013. Practice as Research in the Arts: Principles, Protocols, Pedagogies, Resistances (Basingstoke, Palgrave Macmillan)

Partridge, C. 2013. The Lyre of Orpheus: Popular Music, the Sacred, and the Profane (Oxford; Oxford UP)

Pedelty, M. 2012. Ecomusicology: Rock, Folk, and the Environment (Philadelphia, Temple UP)

Pratt, R. 1994. Rhythm and Resistance: Explorations in the Political Uses of Popular Music (New York, Praeger)

RAC. 2014. RAC Report on Motoring 2014 Britain on the road. Available at:

http://www.rac.co.uk/pdfs/report-on-motoring/rac-rom-2014-v16-compressed [last accessed 2/3/2017]

Raco M. and Imrie R. 2000 'Governmentality and Rights and Responsibilities in Urban Policy’, Environment and Planning A, 32(12), pp.2187-204.

Redclift, M. 2005. 'Sustainable Development (1987-2005): An Oxymoron Comes of Age', Sustainable Development 13(4), pp.212-27 
Rehding, A. 2002. 'Eco-musicology', Journal of the Royal Musical Association, 127(2), pp.305-20

Resource Futures and Kambe Events on behalf of Bristol Festivals Forum, 2015.

'Environmentally Friendly Toilets: An analysis of options for Bristol Event Organisers' Robinson, R. 2015. Music Festivals and the Politics of Participation (London, Routledge)

Sandri, O.J. 2013. 'Exploring the role and value of creativity in education for sustainability', Environmental Education Research, 19(6), pp.765-778

Scott, J. \& Scott. D. 2017. 'The portfolio career in practice: Key aspects of building and sustaining a songwriting and performance career in the digital era', In The Singer-Songwriter Handbook eds. J. Williams \& K. Williams (New York City, Bloomsbury Academic) pp. 191206

Scottish Government. 2013. Low Carbon Scotland: Meeting our Emissions Reduction Targets 2013 - 2027. The Second Report on Proposals and Policies, p.9

T in the Park website. 2016. 'To the best audience in the world...' http://tinthepark.com/ Tjora, A. 2016. 'The social rhythm of the rock festival', Popular Music, 35(1), pp.64-83

UK Government. 2003. Water Environment and Water Services (Scotland) Act, http://www.legislation.gov.uk/asp/2003/3/contents 
UK Music. 2015. Wish you were here 2015: music tourism's contribution to the UK economy (London, UK Music)

Walsh, C.A., Rutherford, G. \& Crough, M. 2013. 'Arts-based research: Creating social change for incarcerated women' Creative Approaches to Research, 6(1), pp.119-139

Webster, E. and McKay, G. 2016. From Glyndebourne to Glastonbury: The Impact of British Music Festivals (Norwich, Arts and Humanities Research Council / University of East Anglia)

Williamson, J. and Cloonan, M. 2007. 'Rethinking the music industry', Popular Music, 26(2), pp.305-322

Woodward, D.I., Taylor, D.J., and Bennett, P.A. 2014. The Festivalization of Culture (Farnham, Ashgate)

Zammit-Lucia, J. 2013. 'The art of sustainability: imagination, not spreadsheets will create change' The Guardian, Friday $24^{\text {th }}$ May. 